\title{
Germanium-76 Sample Analysis
}

Richard T Kouzes

Mark Engelhard

Zihua Zhu

April 2011

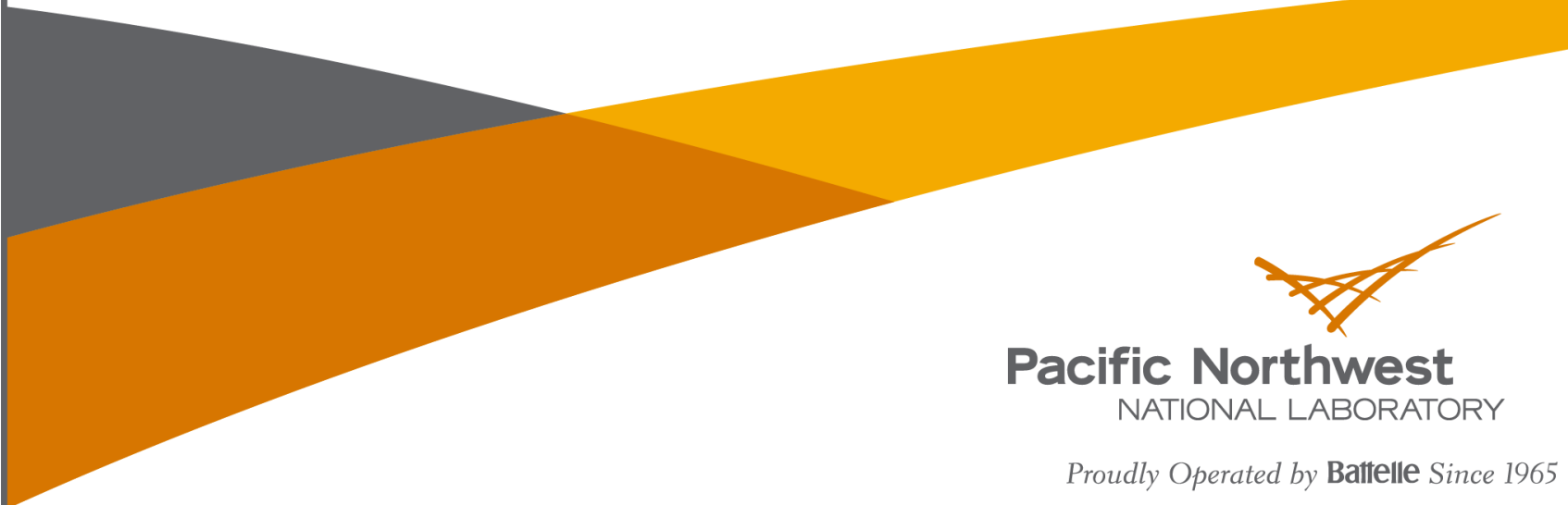




\title{
DISCLAIMER
}

This report was prepared as an account of work sponsored by an agency of the United States Government. Neither the United States Government nor any agency thereof, nor Battelle Memorial Institute, nor any of their employees, makes any warranty, express or implied, or assumes any legal liability or responsibility for the accuracy, completeness, or usefulness of any information, apparatus, product, or process disclosed, or represents that its use would not infringe privately owned rights. Reference herein to any specific commercial product, process, or service by trade name, trademark, manufacturer, or otherwise does not necessarily constitute or imply its endorsement, recommendation, or favoring by the United States Government or any agency thereof, or Battelle Memorial Institute. The views and opinions of authors expressed herein do not necessarily state or reflect those of the United States Government or any agency thereof.

\author{
PACIFIC NORTHWEST NATIONAL LABORATORY \\ operated by \\ BATTELLE \\ for the \\ UNITED STATES DEPARTMENT OF ENERGY \\ under Contract DE-AC05-76RL01830
}

Printed in the United States of America
Available to DOE and DOE contractors from the Office of Scientific and Technical Information,
P.O. Box 62, Oak Ridge, TN 37831-0062;
ph: (865) 576-8401
fax: $(865)$ 576-5728
email: reports@adonis.osti.gov

\begin{abstract}
Available to the public from the National Technical Information Service, U.S. Department of Commerce, 5285 Port Royal Rd., Springfield, VA 22161 ph: (800) 553-6847 fax: $(703) 605-6900$ email: orders@ntis.fedworld.gov online ordering: http://www.ntis.gov/ordering.htm
\end{abstract}

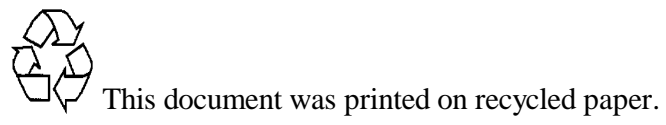


PNNL-20368

\section{Germanium-76 Sample Analysis}

Richard T Kouzes

Mark Engelhard

Zihua Zhu

April 2011

Pacific Northwest National Laboratory

Richland, Washington 99352 


\section{Executive Summary}

The MAJORAna DEMONSTRATOR is a large array of ultra-low background high-purity germanium detectors, enriched in ${ }^{76} \mathrm{Ge}$, designed to search for zero-neutrino double-beta decay $(0 v \beta \beta)$. The DEMONSTRATOR will utilize ${ }^{76} \mathrm{Ge}$ from Russia, and the first one gram sample was received from the supplier for analysis on April 24, 2011. The Environmental Molecular Sciences facility, a DOE user facility at PNNL, was used to make the required isotopic and chemical purity measurements that are essential to the quality assurance for the MAJORANA DEMONSTRATOR. The results of this first analysis are reported here. 


\section{Acronyms and Abbreviations}

$\mathrm{BE}$

EMSL

FWHM

PNNL
Binding Energy

Environmental Molecular Sciences Laboratory

Full width at half maximum

Pacific Northwest National Laboratory 


\section{Contents}

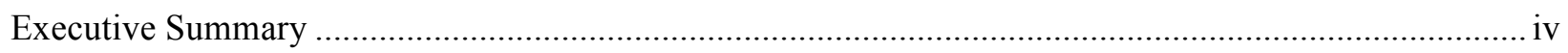

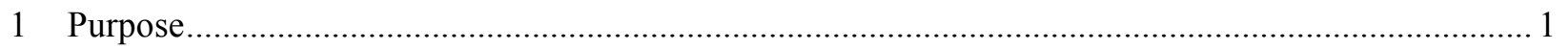

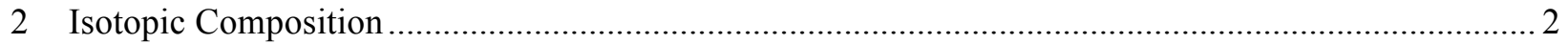

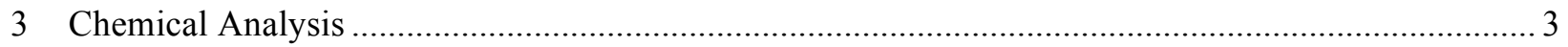

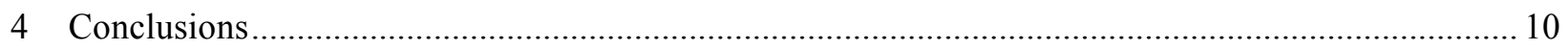

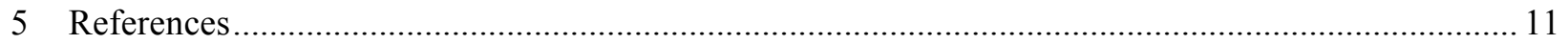




\section{Figures and Tables}

\section{Figures}

Figure 2.1. ToF-SIMS Mass Spectrometer Model Used for Isotopic Measurements............................... 2

Figure 3.1. PHI Quantera XPS with inert atmosphere glove box for inert sample transfer. XPS is on the

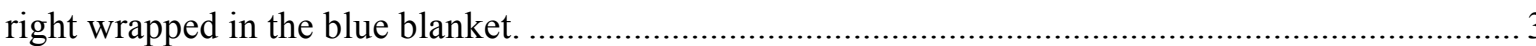

Figure 3.2. PHI Quantera XPS and connecting catalytic side chamber for in-situ controlled pressure and

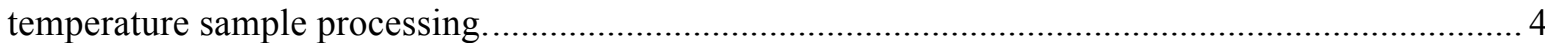

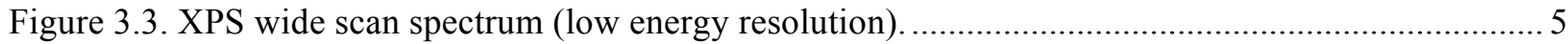

Figure 3.4. XPS narrow scan spectra (high energy resolution) for $\mathrm{Ge} 3 \mathrm{~d}$ region. ...................................... 6

Figure 3.5. XPS narrow scan spectra (high energy resolution) for $\mathrm{O}$ 1s region. ....................................... 7

Figure 3.6. XPS narrow scan spectra (high energy resolution) for Ge $2 \mathrm{p}$ region. ................................... 8

Figure 3.7. XPS narrow scan spectra (high energy resolution) for $\mathrm{C}$ 1s region....................................... 9

\section{Tables}

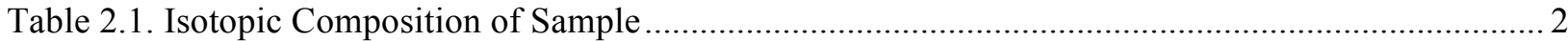

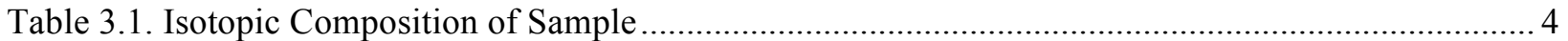




\section{Purpose}

With the results from Super-Kamiokande, SNO, KamLAND, and other neutrino experiments, it has been demonstrated that neutrinos are massive, change flavor, and play an important role in the universe. Measuring the absolute mass of neutrinos and determining their Majorana nature are two of the most important goals of the physics community today. The standard double-beta decay process results in emission of two beta particles and two neutrinos, a process that was first reliably observed in ${ }^{76} \mathrm{Ge}$ by the PNNL-University of South Carolina collaboration in 1990. The much rarer, and yet unconfirmed, $0 v \beta \beta$ process results in emission of only the two beta particles. Observation of this process would provide direct evidence that neutrinos are Majorana particles and that lepton number is not conserved.

The MAJORANA Collaboration was initiated in 1999 in order to carry out a $0 v \beta \beta$ experiment in ${ }^{76} \mathrm{Ge}$. MAJORANA is a collaboration of about 100 scientists at 20 institutions worldwide supported by DOE Office of Science Office of Nuclear Physics, the National Science Foundation, and other international funding agencies. The current plan calls for the MAJORANA DEMONSTRATOR to be constructed and operated over the next several years in parallel with the European ${ }^{76} \mathrm{Ge}$ experiment (GERDA). This is proposed to be followed by a single, merged, Tonne-Scale, international experiment for $0 v \beta \beta$ in ${ }^{76} \mathrm{Ge}$.

The MAJORANA DEMONSTRATOR experiment is now constructing an essentially background-free measurement of $0 v \beta \beta$ in $30 \mathrm{~kg}$ of natural Ge plus $30 \mathrm{~kg}$ of ${ }^{76} \mathrm{Ge}$ with the goal of determining lepton number conservation and the neutrino mass. The MAJORANA DEMONSTRATOR requires 30 $\mathrm{kg}$ of isotopically enriched ${ }^{76} \mathrm{Ge}$. Currently, the only source of enriched ${ }^{76} \mathrm{Ge}$ is from Russia, at a cost of $\sim \$ 85 / \mathrm{g}$. This material will be delivered to the MAJORANA DEMONSTRATOR experiment in FY11-FY12, with quality assurance (QA) samples arriving on a periodic basis during this time. These QA samples will require precision isotopic evaluation. One such measurement was performed in 2009 under an EMSL rapid proposal on a single sample using SIMS instruments [Elliott 2009]. Further measurements will take place during FY11-FY12 at EMSL.

Reported here are the results of the first measurements of isotopic composition and chemical purity of a sample of ${ }^{76} \mathrm{Ge}$ delivered by Isoflex, the representative of ECP in Russia. The onegram sample of ${ }^{76} \mathrm{GeO}_{2}$ was delivered to PNNL on April 25, 2011 for analysis, which was completed on April 27, 2011. The measurements were made in the Environmental Molecular Sciences Laboratory at PNNL under EMSL user proposal \#43992. 


\section{Isotopic Composition}

A time-of-flight secondary ion mass spectrometry (ToF-SIMS) system, of the type shown in Figure 2.1, at EMSL was used for the isotopic analysis of the Russian ${ }^{76} \mathrm{Ge}$ sample. Table 2.1 provides the results of the isotopic analysis, where the value in parenthesis is the uncertainty in the last digit.

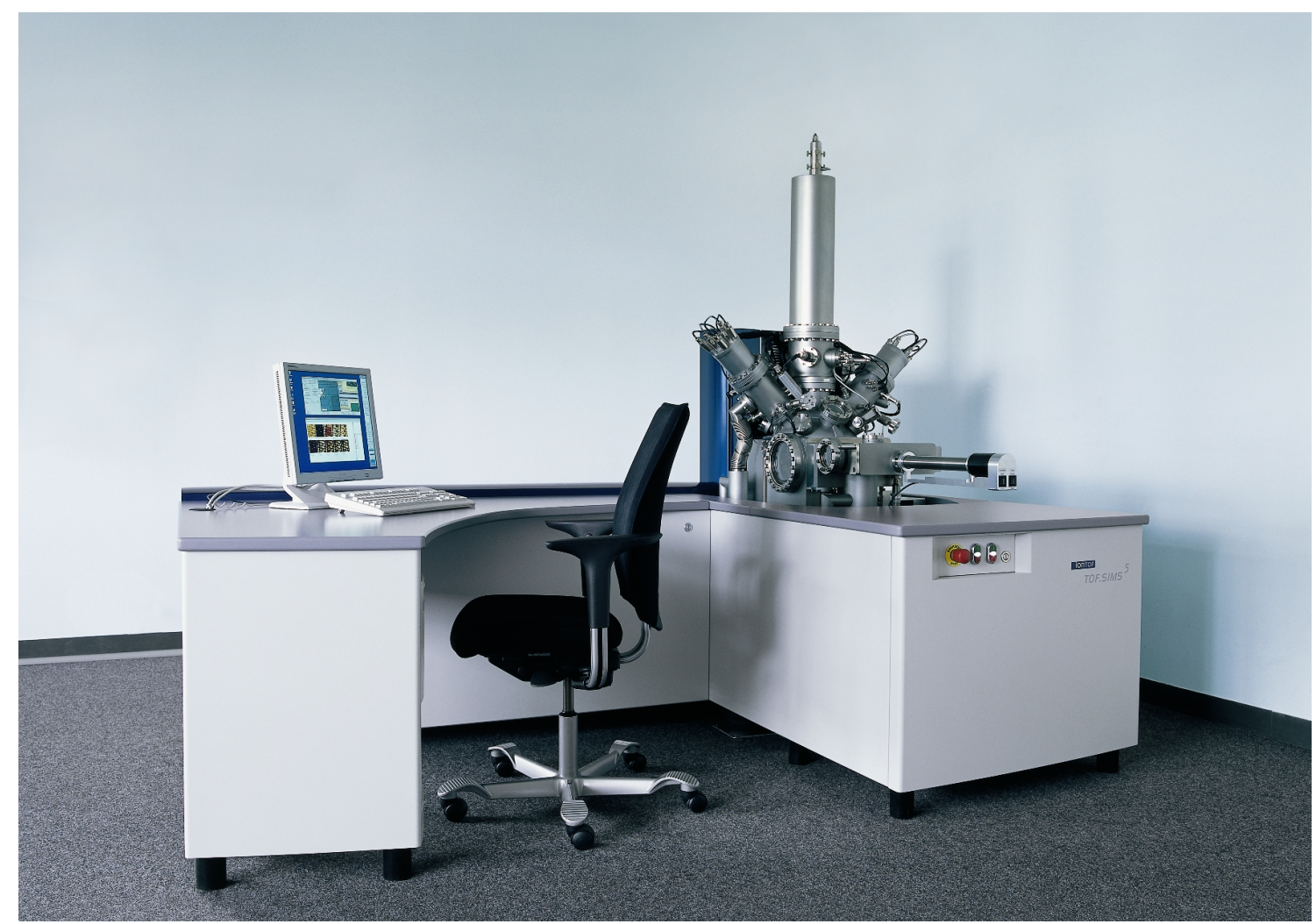

Figure 2.1. ToF-SIMS Mass Spectrometer Model Used for Isotopic Measurements

Table 2.1. Isotopic Composition of Sample

\begin{tabular}{|c|c|}
\hline Isotope & Fractional Composition \\
\hline${ }^{70} \mathrm{Ge}$ & $0.00006(1)$ \\
\hline${ }^{72} \mathrm{Ge}$ & $0.00011(1)$ \\
\hline${ }^{73} \mathrm{Ge}$ & $0.00033(3)$ \\
\hline${ }^{74} \mathrm{Ge}$ & $0.086(5)$ \\
\hline${ }^{76} \mathrm{Ge}$ & $0.914(5)$ \\
\hline
\end{tabular}




\section{Chemical Analysis}

X-ray photoelectron spectroscopy (XPS) was used to perform the chemical purity analysis. XPS is more surface sensitive and provides relative concentration and chemical state information.

XPS measurements were performed with a Physical Electronics Quantera Scanning X-ray Microprobe. This system uses a focused monochromatic Al Ka X-ray $(1486.7 \mathrm{eV})$ source for excitation and a spherical section analyzer. The instrument has a 32-element multichannel detection system. A $100 \mathrm{~W}$ Xray beam focused to $100 \mu \mathrm{m}$ diameter was rastered over a $1.4 \mathrm{~mm}$ x $0.1 \mathrm{~mm}$ rectangle on the sample. The X-ray beam is incident normal to the sample and the photoelectron detector is at $45^{\circ}$ off normal. High energy resolution spectra were collected using a pass-energy of $69.0 \mathrm{eV}$ with a step size of 0.125 $\mathrm{eV}$. For the Ag 3d5/2 line, these conditions produced a full width at half maximum (FWHM) of 0.91 $\mathrm{eV}$. The sample experienced variable degrees of charging. Low energy electrons at $\sim 1 \mathrm{eV}, 20 \mu \mathrm{A}$ and low energy $\mathrm{Ar}^{+}$ions were used to minimize this charging. The binding energy (BE) of adventitious carbon line was set at $284.8 \mathrm{eV}$ to compensate for any surface-charging effects.

The $\mathrm{GeO}_{2}$ powder samples were pressed onto clean double sided Nichiban tape supported by 1 $\mathrm{cm} \times 3 \mathrm{~cm}$ flat Si wafers. The sample holder was then placed into the XPS vacuum introduction system and pumped to less than $1 \times 10^{-6}$ Torr using a turbomolecular pumping system prior to introduction into the main ultra high vacuum system. The main vacuum system pressure is maintained at less than $5 \times 10^{-9}$ Torr during analysis and pumped using a series of sputter ion pumps.

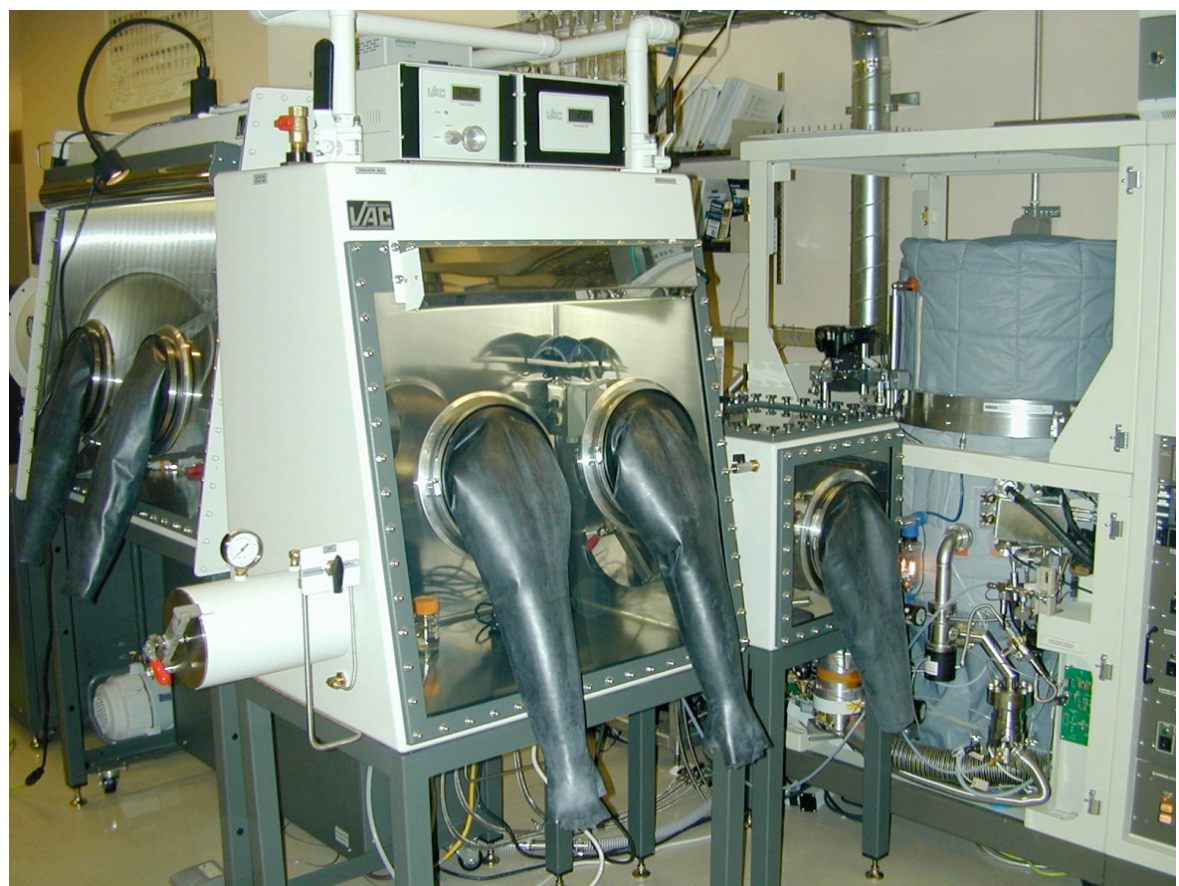

Figure 3.1. PHI Quantera XPS with inert atmosphere glove box for inert sample transfer. XPS is on the right wrapped in the blue blanket. 


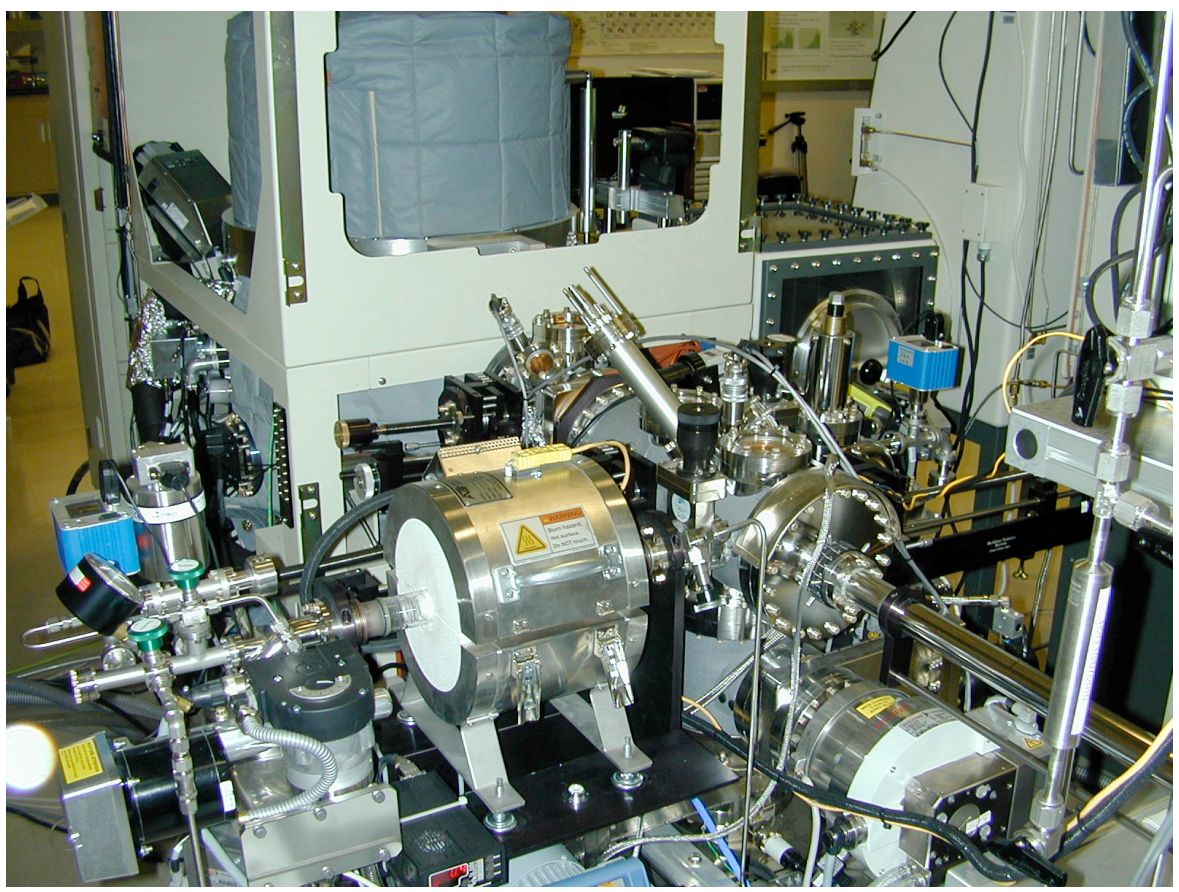

Figure 3.2. PHI Quantera XPS and connecting catalytic side chamber for in-situ controlled pressure and temperature sample processing.

Figures 3.1 and 3.2 show two views of the XPS system in EMSL.

\section{XPS Results}

Calculated atomic concentrations for sample number $1-\mathrm{A}^{76} \mathrm{GeO}_{2}$ from the high-energy resolution narrow scan (spectral output file 02261.103). Figure 3.3 shows the broad energy range spectrum obtained. Figures $3.4-3.7$ show high resolution scans of specific peaks.

Table 3.1 shows the measurement results for the three observed elements: Ge, $\mathrm{O}$, and $\mathrm{C}$. The Relative sensitivity factor (RSF) is corrected for specific instrument effects and is used to derive the atomic percentages shown. From these values, the XPS quantified ratio of $\mathrm{Ge} / \mathrm{O}$ is 0.52 , compared to the expected $\mathrm{Ge} / \mathrm{O}$ ratio of 0.50 .

Table 3.1. Isotopic Composition of Sample

\begin{tabular}{|r|c|c|c|}
\hline Element: & C1s & O1s & Ge3d \\
\hline Relative sensitivity factor (RSF) & 0.314 & 0.733 & 0.535 \\
\hline RSF corrected for specific instrument & 21.075 & 49.679 & 41.210 \\
\hline Atomic Percent & 5.4 & 62.3 & 32.3 \\
\hline
\end{tabular}

\section{Contamination}

Approximately 5.4 atomic percent carbon was detected on the surface of the sample, which is consistent with adventitious hydrocarbons typically detected on surfaces exposed to atmosphere. No other contaminants were observed above the background level of 0.5 atomic percent. 


\section{Chemical States (Measured Binding Energies And Reference Energies)}

Both the Ge 2p3 and $\mathrm{O}$ 1s photoemission line energies of 1220.8 and $532.1 \mathrm{eV}$, respectively, are consistent within $\pm 0.2 \mathrm{eV}$ of reference line energies published in the NIST Standard Reference Database 20, Version 3.5. The Ge 2p3 reference line energy for $\mathrm{GeO}\left(\mathrm{Ge}^{+2}\right)$ is $1221.5 \mathrm{eV}$, whereas it would be $1217.4 \mathrm{eV}$ for Ge metal $\left(\mathrm{Ge}^{0}\right)$, verifying that the observed material is $\mathrm{GeO}_{2}$.

The germanium (IV) dioxide $\left(\mathrm{GeO}_{2}\right)$ XPS binding energy references are: Wagner [1975] for Ge2p3 (1220.6 eV), Wagner et al. [1980] for O 1s (531.9 eV), and Nefedov et al. [1975] for O1s $(532.2 \mathrm{eV})$.

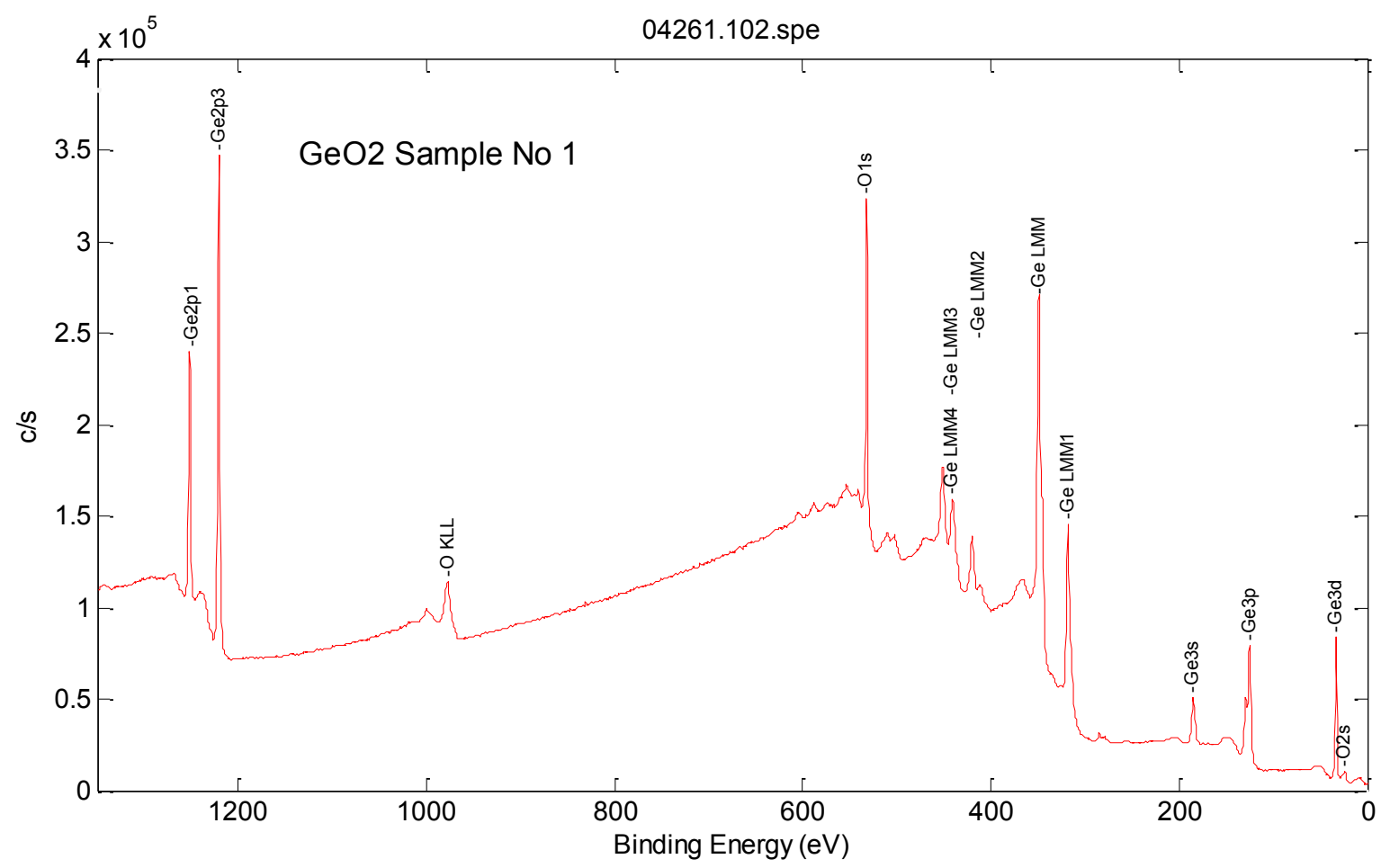

Figure 3.3. XPS wide scan spectrum (low energy resolution). 


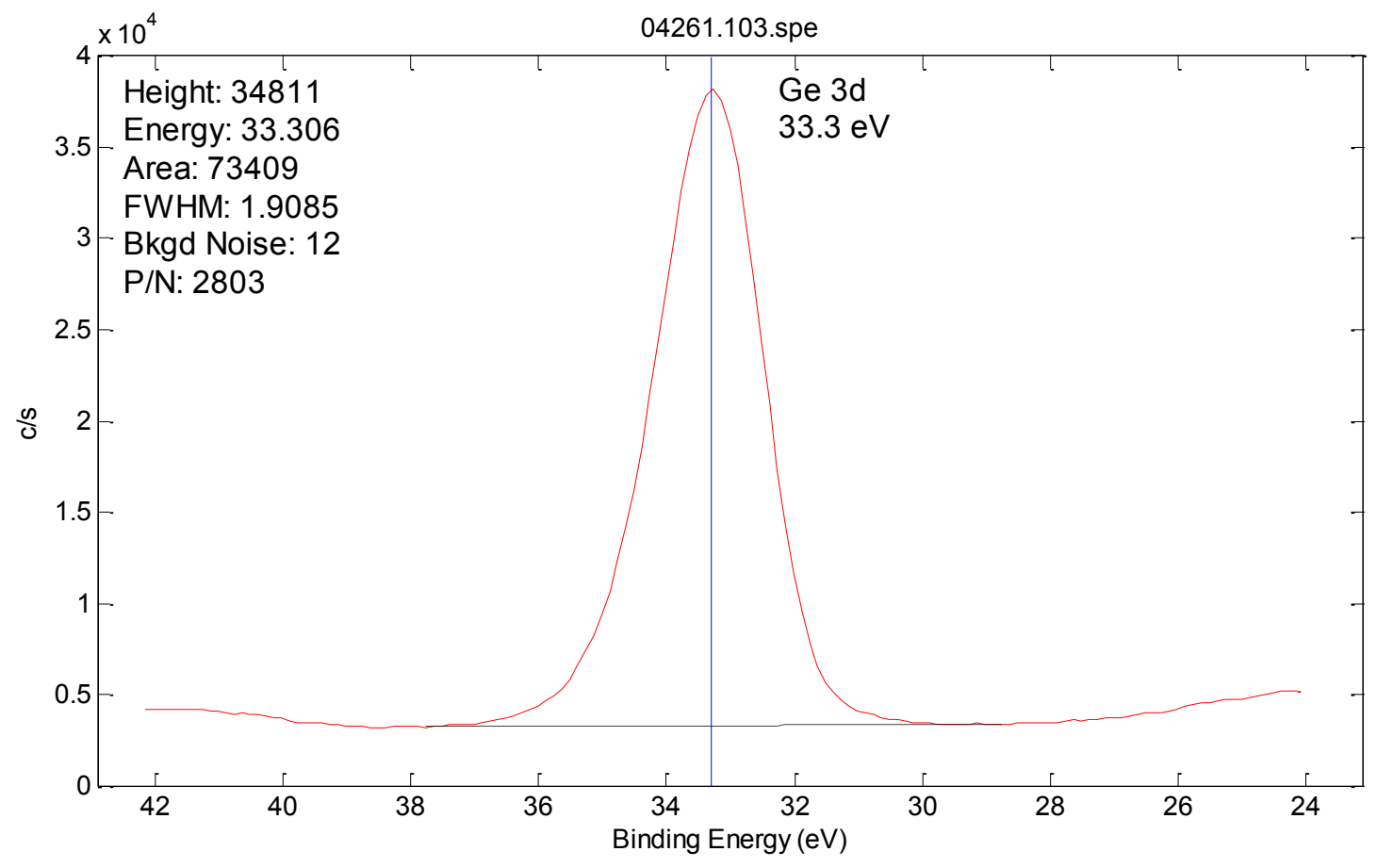

Figure 3.4. XPS narrow scan spectra (high energy resolution) for Ge $3 \mathrm{~d}$ region. 


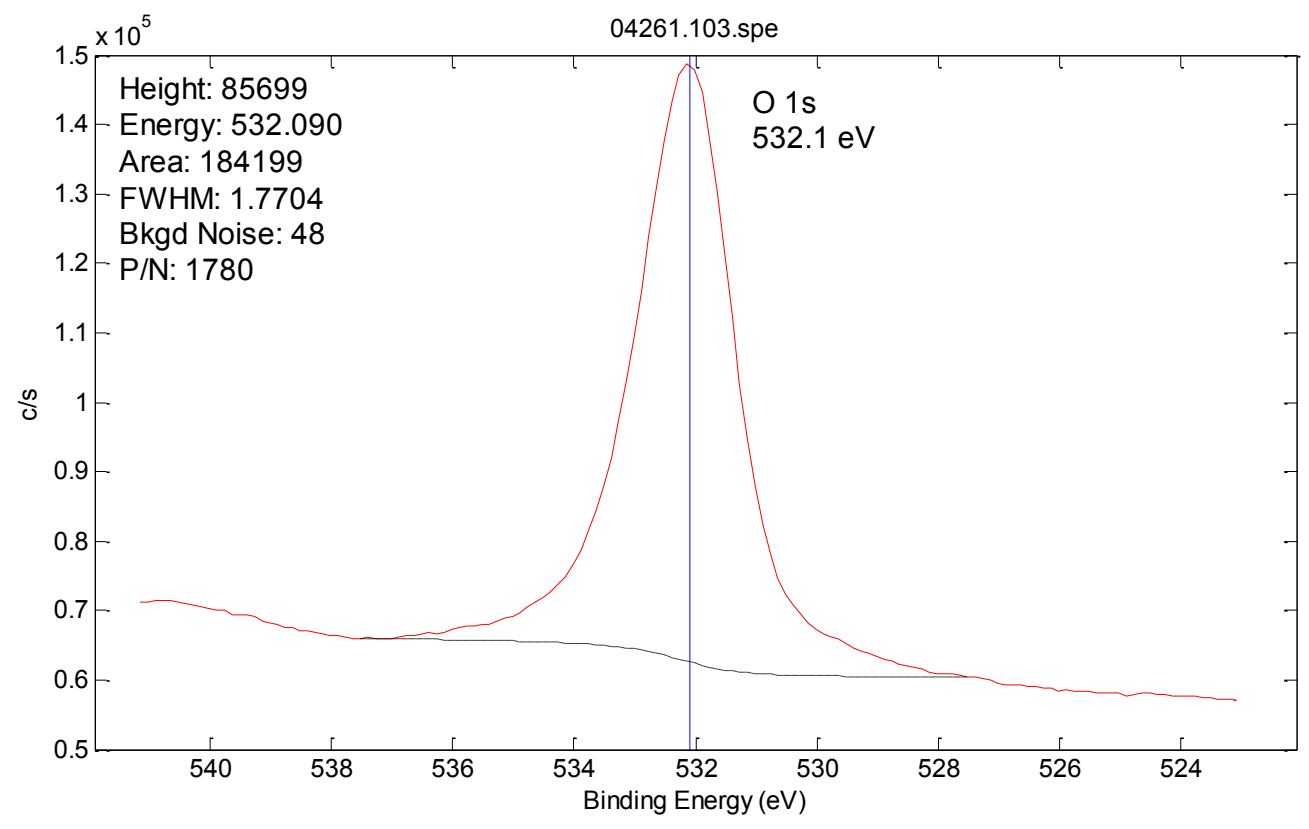

Figure 3.5. XPS narrow scan spectra (high energy resolution) for O 1 s region. 


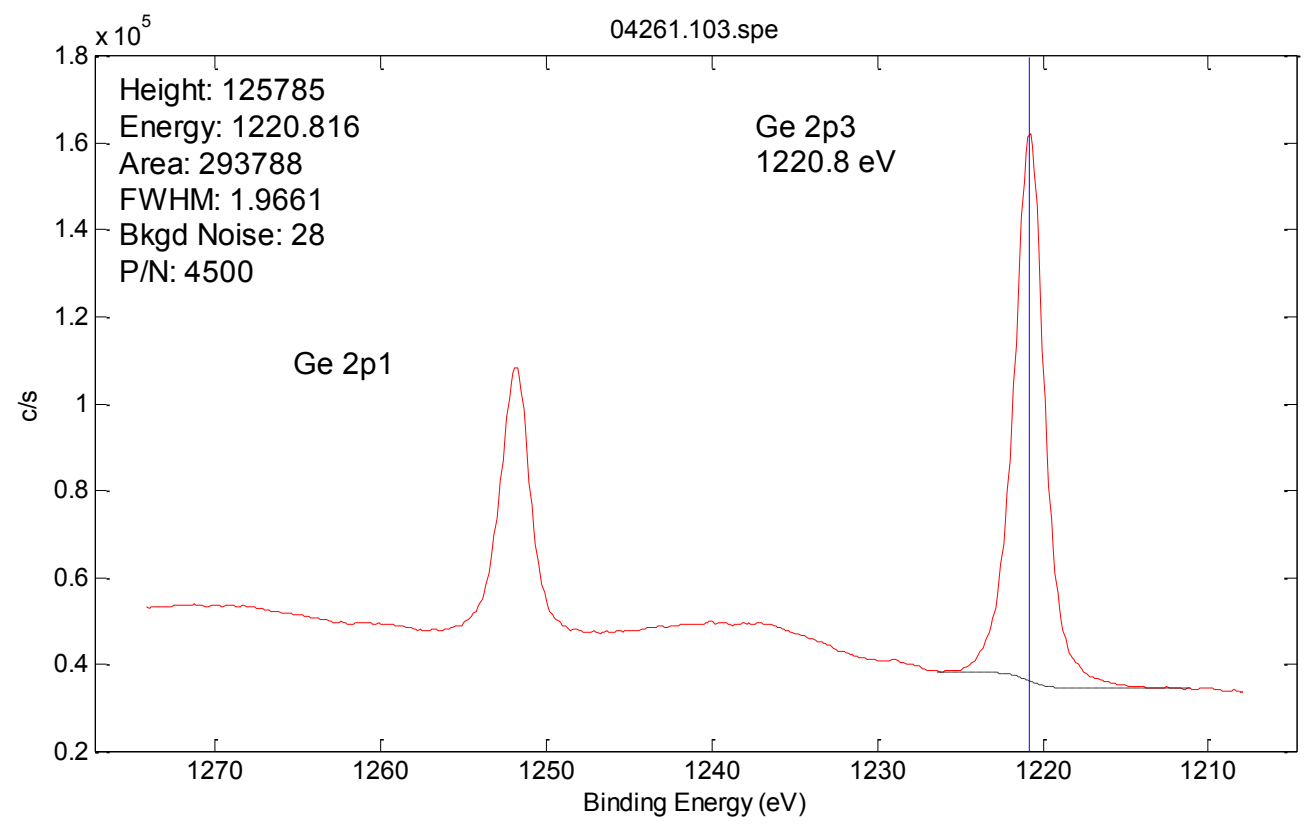

Figure 3.6. XPS narrow scan spectra (high energy resolution) for Ge $2 p$ region. 


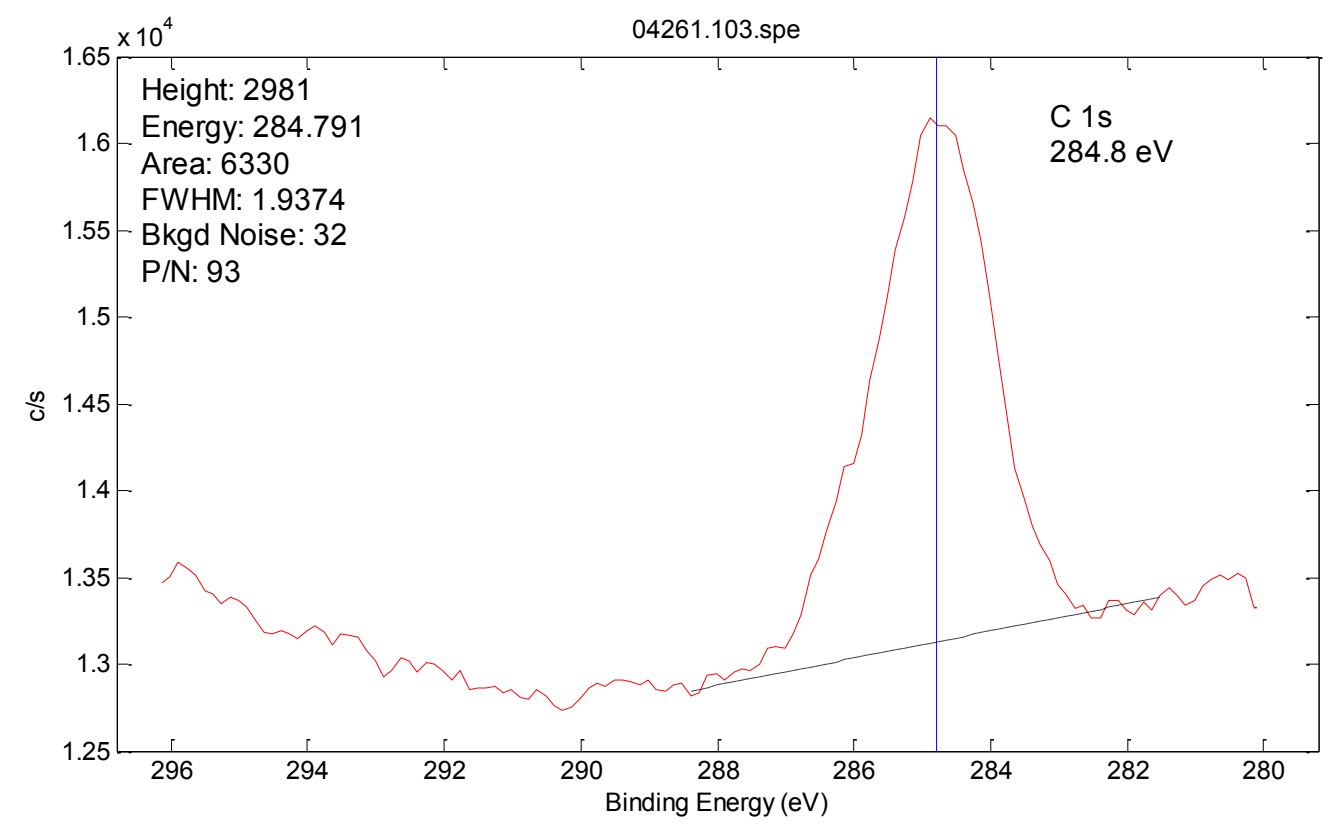

Figure 3.7. XPS narrow scan spectra (high energy resolution) for $\mathrm{C} 1 \mathrm{~s}$ region. 


\section{Conclusions}

The results of the isotopic composition of the ${ }^{76} \mathrm{GeO}_{2}$ sample from Russia showed higher than expected enrichment. The chemical purity of the sample is consistent with a $\mathrm{GeO} 2$ sample and shows no contamination above background at 0.5 atomic percent. 


\section{References}

Elliott S.R., V.E. Guiseppe, B.H. LaRoque, R.A. Johnson, S.G. Mashnik, Fast-Neutron

Activation of Long-Lived Isotopes in Enriched Ge, submitted for publication December 2009.

Nefedov V.I., Gati D., Dzhurinskii, B.F., Sergushin N.P., Salyn Y.V. Zh. Neorg. Khimii 20, 2307 (1975)

Wagner C.D., Discuss. Faraday Soc. 60, 291 (1975)

Wagner C.D., Zatko D.A., Raymond R.H. Anal. Chem. 52, 1445 (1980) 


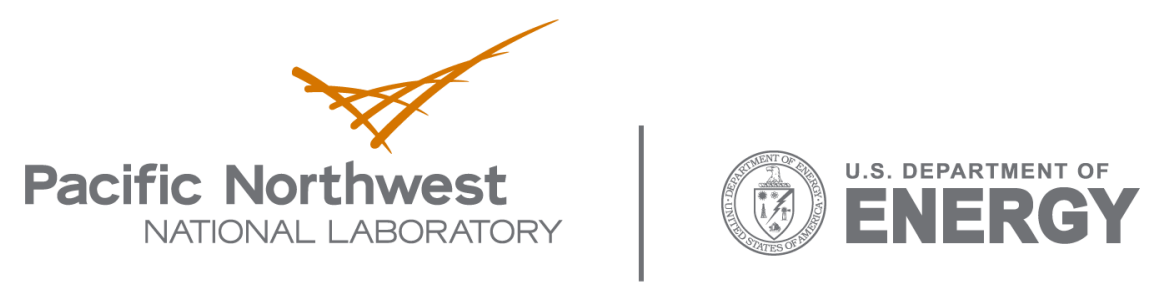

902 Battelle Boulevard

P.O. Box 999

Richland, WA 99352

1-888-375-PNNL (7665)

www.pnl.gov 